\title{
KONSTRUKSI SOSIAL REALITAS MASYARAKAT INDONESIA DI TENGAH KONTEN PENYIARAN TELEVISI YANG JAKARTASENTRIS
}

\author{
Eric Fernardo ${ }^{1}$
}

\begin{abstract}
ABSTRAK
Konten penyiaran televisi di Indonesia tersentralisasi pada berita Jakarta, gaya hidup Jakarta, maupun tata bahasa tentang Jakarta. Agar dapat menghasilkan keuntungan, stasiun televisi bersama-sama menyajikan siaran yang Jakartasentris untuk mengejar rating yang bias Jakarta dan secara ironis keuntungan tersebut hanya dinikmati oleh sebagian besar industri televisi yang berkantor di Jakarta. Dominasi konten Jakartasentris ini harus disaksikan oleh seluruh penduduk Indonesia secara berulang-ulang. Penelitian ini menggunakan pisau analisa konstruksi sosial realitas dan teori kultivasi menemukan bahwa konten penyiaran yang Jakartasentris membentuk sosial realitas antara lain masyarakat luar Jakarta merasa bahwa bergaya Jakarta itu keren dan prestise sementara masyarakat Jakarta menilai bahwa orang yang tidak bergaya Jakarta sebagai kampungan ataupun aneh.
\end{abstract}

Kata kunci: Televisi, Jakartasentris, Sosial Realitas, Kultivasi

\section{ABSTRACT}

Indonesia television content was centralized into everything about Jakarta like Jakarta news, Jakarta lifestyle, even Jakarta languange. To maximize its functions in order to generate profits, television station pursue rating that was biased Jakarta, ironically the profits generated only enjoyed by television stations based in Jakarta. Domination content of Jakartasentris must be watched by all of Indonesian people repeatedly. Using social reality and cultivation theory, this research found that Jakartasentris television content have an impact on social reality, people outside Jakarta think using Jakarta style was cool and more prestige while Jakartans think that people who do not use Jakarta style were weird.

Keywords: Television, Jakartasentris, Social Reality, Cultivation

${ }^{1}$ FISIP, Universitas Indonesia, Jakarta, Indonesia. Email: eric.fernaRdo01@ui.ac.id 


\section{PENDAHULUAN}

Ketika menyebut kata media, kita dapat langsung membayangkan berbagai peralatan yang menjadi medium atau perantara penyebaran informasi seperti radio, koran, internet ataupun televisi. Namun, medium atau perantara tersebut tidaklah cukup menggambarkan secara komprehensif makna sesungguhnya dari media. Secara linguistik, media merupakan penjabaran dari medium dimana medium merupakan sesuatu yang berada di antara dua pihak, dalam konteks komunikasi media merupakan perantara yang digunakan pengirim pesan untuk disalurkan dan diterima penerima pesan (Long \& Wall, 2012). Selain media, penggunaan yang sering digunakan adalah kata media massa yakni sebuah medium yang dapat mengirimkan pesan dari satu sumber kepada banyak pihak sekaligus secara simultan dan dapat diterima oleh penerima pesan dalam jumlah banyak. Dalam media massa, pengirim pesan tidak menentukan siapa yang menjadi penerima pesannya, yang mana hal ini berbeda jika manusia menggunakan media komunikasi seperti telepon, jika menggunakan telepon tentunya kita akan menentukan terlebih dahulu siapa yang menjadi penerima pesan (Long \& Wall, 2012).

Dalam media massa tidak ada interaksi untuk mencapai kesepakatan antara pengirim pesan dan penerima pesan, sehingga makna 'massa' menjelaskan jumlah penerima pesan yang banyak seperti televisi, radio (Luhmann, 2000). Dalam perkembangannya di Indonesia, media massa memainkan peran penting dalam konstruksi sosial realitas masyarakat, misalnya sewaktu Soekarno memproklamasikan kemerdekaan Indonesia pada 17 Agustus 1945, kabar tentang proklamasi kemerdekaan segera disebarkan ke seluruh penjuru negeri agar penduduk mengetahui terbentuknya Negara Kesatuan Republik Indonesia (NKRI) dan mendukung kemerdekaan tersebut, kabar kemerdekaan segara diberitakan melalui radio, koran, kantor berita Antara, maupun pamflet, poster, spanduk (Utami, 2015).

Terkait perkembangan televisi di Indonesia sejak era kemerdekaan, siaran televisi pertama adalah liputan perayaan hari ulang tahun kemerdekaan Indonesia yang ke-17 pada tanggal 17 Agustus 1962, beberapa hari setelahnya warga Jakarta dapat menyaksikan siaran langsung pembukaan Asian Games pada 24 Agustus 1962 yang kini diperingati sebagai hari lahirnya Televisi Republik Indonesia atau yang akrab disingkat TVRI (Arsan, 2016). TVRI tercatat selama dua puluh tujuh tahun dari tahun 1962-1989 menjadi pemain tunggal atau memonopoli siaran televisi di Indonesia, sebagai stasiun televisi yang dimiliki pemerintah Indonesia dan berada di bawah Departemen Penerangan, tentunya TVRI harus tunduk pada keputusan pemerintah yang berkuasa, isi siaran harus selaras dengan kepentingan pembangunan dan stabilitas politik 
penguasa oleh karenanya dalam kurun waktu monopoli TVRI tidak muncul perdebatan terkait penataan penyiaran di Indonesia, tidak ada isu kompetisi maupun kepemilikan (Armando, 2011).

Barulah pada 24 Agustus 1989, muncul stasiun televisi swasta pertama di Indonesia yakni Rajawali Citra Televisi Indonesia (RCTI) dan ditandai kemunculan stasiun televisi swasta lainnya seperti Surya Citra Televisi (SCTV), TPI, Indosiar dan seterusnya (Ishadi, 2011). Dalam perkembangan media massa di Indonesia, terdapat dua belas grup konglomerasi dan satu lembaga penyiaran publik milik pemerintah yang mendominasi media di Indonesia antara lain lembaga penyiaran publik, Media Nusantara Citra (MNC) Group, Mahaka Media Group, Kompas Gramedia Group, Jawa Pos Group, Media Bali Post Group, Elang Mahkota Teknologi (EMTEK) Group, Lippo Group, Bakrie \& Brothers (Visi Media Asia), Femina Group, Media Group (Metro TV), Mugi Reka Abadi (MRA) Group, Trans Corpora (Para) Group (Merlyna, 2012).

Terkhusus untuk televisi, di Indonesia sekurang-kurangnya terdapat seratus stasiun televisi di tingkat lokal, namun untuk stasiun televisi nasional hanya terdapat 6 pemain utama dari sektor swasta dan satu stasiun televisi milik pemerintah yakni TVRI, stasiun televisi swasta tingkat nasional hanya dimiliki oleh enam grup konglomerasi yakni pertama MNC Group dengan pemimpin utamanya Hary Tanoesoedibjo melalui RCTI, Global TV, MNC TV; kedua Kompas Gramedia Group dengan pemimpin utamanya Lilik Oetama (dahulu Alm. Jakob Oetama) melalui Kompas TV; ketiga EMTEK Group dengan pemimpin utama Eddy Kusnadi Sariaatmadja melalui SCTV dan Indosiar; keempat Bakrie \& Brothers dengan pemimpin utama Anindya Bakrie (anak dari Aburizal Bakrie) melalui ANTV dan TVOne; kelima Media Group dengan pemimpin utama Surya Paloh melalui Metro TV; keenam Trans Corpora (Para Group) dengan pemimpin utama Chairul Tanjung melalui Trans TV dan Trans 7 (Merlyna, 2012).

Media di satu sisi dapat mendorong proses transparansi informasi namun, perlu diingat selain menjadi entitas yang mengejar keuntungan, dominasi kepemilikan media di Indonesia oleh konglomerasi, dapat mempengaruhi produksi konten sehingga konten-konten yang diproduksi berpihak pada kepentingan pemiliknya (Nugroho dkk, 2013), selain persoalan kepemilikan media di Indonesia yang didominasi oleh kelompok konglomerasi tertentu, masalah lain yang menjadi krusial adalah soal konten atau isi penyiaran, dalam riset yang dilakukan oleh Nugroho dan kawan-kawan di tahun 2013 melalui metode analisis konten terhadap tayangan televisi, ditemukan hasil bahwasannya tidak ada keberagaman konten dalam media Indonesia, isi media Indonesia 
secara spasial sangat berpusat pada gambaran tentang Ibukota Jakarta, dalam konteks keagamaan sangat didominasi oleh penggambaran agama Islam serta dalam identitas etnis didominasi oleh budaya Jawa.

Keseragaman konten media dipengaruhi oleh kepentingan untuk menghasilkan keuntungan sehingga kontenkonten yang diproduksi akan berpacu pada pola yang sudah pasti akan menghasilkan keuntungan sehingga terjadilah pemusatan konten dimana konten yang dihasilkan antara satu media dengan media lainnya sama dengan tingkat keberagaman yang rendah, hal ini menimbulkan potensi terpinggirnya kelompok minoritas karena konten-konten yang diproduksi hanya menggambarkan kelompok mayoritas semata (Nugroho dkk, 2013). Televisi sebagai media massa yang dapat diakses $91 \%$ penduduk Indonesia dan ditonton setidaknya oleh penduduk seminggu sekali (Merlyna, 2011).

Dalam karyanya, berjudul The Social Construction of Reality: A Treatise The Sociology of Knowledge di tahun 1966, Peter Ludwig Berger dan Thomas Luckmann menyampaikan bahwa realitas merupakan hasil konstruksi sosial, dan untuk menganalisis hal tersebut diperlukan pengetahuan sosiologi (Berger \& Luckmann, 1966). Manusia menghasilkan realitas berdasarkan hasil interaksi dengan struktur sosial yang selanjutnya terjadi objektivasi dimana temuan baru manusia menjadi bagian dari realitas dan proses reifikasi yakni tahapan realitas dianggap bukan hasil ciptaan manusia (Berger \& Luckmann, 1966).

'Realitas' dan 'pengetahuan' menjadi dua kata kunci utama dalam karya Berger \& Luckmann bahwasannya realitas adalah hal objektif yakni fakta sosial yang bersifat eksternal, umum serta mampu memaksa kesadaran tiap individu baik hal tersebut disukai maupun tidak, sementara pengetahuan adalah hal subyektif yakni realitas yang hadir dalam kesadaran individu. Realitas sosial terjadi dan dialami individu saat berinteraksi dengan individu lainnya yang dikenal dengan istilah eksternalisasi; selanjutnya objektivasi berupa proses menghasilkan objek yang menampilkan maksud subyek pelaku, terdapat proses penting dalam objektivasi yakni produksi isyarat yang disebut signifikansi berupa proses penandaan oleh manusia dan perlu diketahui juga pertukaran bahasa menghasilkan pengetahuan (Berger \& Luckmann, 1966).

Realitas objektif dalam masyarakat muncul karena individu mengeksternalisasi dirinya melalui aktivitas untuk menggunakan pemikirannya dalam mempertahankan hidup, aktivitas yang diulang-ulang akan membentuk habituasi atau pembiasaan yakni kecenderungan untuk mengulang serangkaian aktivitas saat menghadapi hal-hal yang sama. Dalam habituasi ini kemudian dapat mendorong munculnya tipifikasi, yang akan menghasilkan pranata sosial dan bila telah 
berlaku luas, eksternal maupun koersif pada gilirannya akan menjadi institusi sosial yang ditransmisikan dari satu generasi ke generasi selanjutnya dan tetap terjaga karena legitimasi masyarakat terhadap makna objektif yang terkandung di dalamnya, ketika manusia telah menerima institusi sosial tersebut maka terjadilah proses internalisasi (Berger \& Luckmann, 1966).

Teori kultivasi merupakan salah satu teori yang menjadi pisau analisa dalam mengamati efek media, lebih khusus lagi yakni dalam medium televisi, George Gerbner dan koleganya mengamati selama 5 dekade pengaruh tayangan kekerasan di televisi dan menemukan bahwa konten kekerasan yang terdapat di televisi mempengaruhi konstruksi sosial realitas penonton, secara lebih detail dijelaskan bahwa penonton yang banyak menyaksikan tontonan kekerasan di televisi akan melihat dunia sebagai tempat yang seram dan menakutkan (Dainton, 2019).

Asumsi dari teori kultivasi antara lain pertama, televisi telah menjadi bagian inti dari kehidupan dan budaya yang terbukti dalam konteks Amerika Serikat (Gerbner, 1998). 99\% penduduk di Amerika Serikat setidaknya memiliki satu televisi di rumahnya dan menonton rata-rata lima jam tayangan televisi setiap harinya, di era digital saat ini 50\% masyarakat juga berlanggan siaran streaming seperti Netflix atau Hulu yang menyebabkan konsumsi media lebih dari sepuluh jam setiap harinya (Koblin, 2016). Gerbner meyakini bahwa televisi telah menjadi sumber utama dalam percakapan maupun cerita di Amerika Serikat, bahkan diyakini oleh Gerbner bahwa pengaruh dari televisi sebagai sumber cerita telah melebihi percakapan antarpribadi, buku, bahkan agama (Gerbner, 1998).

Asumsi kedua adalah televisi mempengaruhi konstruksi sosial realitas penonton sehingga membentuk budaya Amerika Serikat termasuk dalam hubungan sosial seseorang maupun cara berpikir seseorang, meskipun televisi hanya menggambarkan bagian-bagian tertentu dari kehidupan sosial yang ditampilkan dalam liputan berita, cerita, drama, komedi. Gerbner berpendapat bahwa pengulangan tayangan kehidupan sosial merupakan sesuatu yang diharapkan oleh penonton (Dainton, 2019).

Asumsi ketiga yang perlu digarisbawahi adalah pengaruh televisi itu terbatas atau tidak tunggal, dalam kata lain televisi bukanlah satusatunya faktor yang mempengaruhi pandangan individu tentang realitas sosial, meskipun televisi diyakini secara konsisten memiliki dampak terhadap individu meskipun tidak besar tetapi pengaruh televisi akan selalu ada dan menciptakan perbedaan yang signifikan dalam cara pandang, merasakan dan berinteraksi seseorang di realitas sosialnya (Gerbner dkk, 1980).

Efek media tidak berlaku bagi semua orang, dalam teori kultivasi diyakini bahwa perubahan konstruksi sosial realitas terjadi 
ketika durasi menonton televisinya meningkat, atau dalam kata lain semakin sering seseorang menonton televisi maka semakin mungkin seseorang memiliki konstruksi sosial realitas sesuai tayangan televisi (Dainton, 2019). Pengaruh dari teori kultivasi juga dapat dicermati dalam riset lain yang dikemukakan oleh Nabi dimana dalam risetnya Nabi menyampaikan bahwa semakin sering seseorang menyaksikan program kecantikan, maka semakin tidak puas dengan penampilannya sehingga semakin tinggi peluangnya untuk menjalankan operasi plastik dibandingkan seseorang yang tidak sering menonton program kecantikan (Nabi, 2009).

Selain pengaruh televisi, peneliti lain juga meneliti efek kultivasi dalam media lain misalnya pengaruh terpaan iklan cetak obatobatan untuk mengatasi depresi dengan perasaan menyimpang seseorang menderita depresi klinis (Park dan Grow, 2008). Media lain yakni pemberitaan di koran tentang kejahatan antar etnis menyebabkan etnis mayoritas merasa terancam oleh etnis minoritas (Vergeer dkk, 2000).

Teori kultivasi menilai ada 2 cara media mengubah konstruksi sosial realitas penonton, yakni arus utama dan resonansi (Gerbner, 1998). Arus utama melihat penonton terutama penonton berat mengembangkan konstruksi sosial realitas berdasarkan seringnya terpaan media atas tayangan berulang dan dominan gambar, cerita dan pesan dari televisi. Dalam arus utama, penggambaran tayangan televisi tentang kehidupan serta-merta akan mempengaruhi konstruksi sosial realitas penonton (Dainton, 2019).

Sementara jika melalui resonansi, asumsinya adalah penonton akan melihat tayangan yang ada di televisi dan membandingkannya dengan pengalaman kehidupannya sendiri, misalnya terkait kekerasan, jika seseorang mengalami pengalaman hidup tentang kekerasan maka ketika menonton tayangan kekerasan di televisi, dirinya akan memutar ulang situasi kehidupannya sendiri. Tayangan kekerasan yang disaksikan di televisi dapat memperkuat ataupun beresonansi dengan pengalaman hidupnya. Hal ini memungkinkan terjadinya akibat yakni penonton akan semakin menyadari bahwa dunia sungguh kejam dan menakutkan sehingga tidak mungkin tidak ada kekerasan ataupun seseorang yang merasa dirinya pernah menjadi korban akan melihat tayangan di televisi sebagai sesuatu yang kemudian dianggap norma dalam masyarakat (Dainton, 2019).

Berangkat dari latar belakang fenomena sentralisasi pemberitaan yang berpusat di Ibukota, riset ini akan mengkaji lebih dalam bagaimana konstruksi sosial realitas masyarakat Indonesia di tengah konten penyiaran televisi yang Jakartasentris. 


\section{METODOLOGI}

Penelitian ini menggunakan metode kualitatif dimana peneliti berupaya untuk menangkap dan menemukan makna mendalam dari suatu peristiwa, analisis dalam riset kualitatif akan mengekstraksi tema berdasarkan temuan yang didapat untuk disajikan secara komprehensif dan konsisten (Neuman, 2014). Studi kualitatif cenderung berangkat dari fenomena sosial yang terjadi di masyarakat untuk dikaji, dan bisa berangkat dari gagasan ataupun ide para peneliti sebelumnya. Penelitian kualitatif mendokumentasikan data dari peristiwa nyata yang terjadi di masyarakat, mengamati pendapat seseorang atas suatu kejadian, ataupun melalui studi kepustakaan yang bertujuan untuk melihat gambaran konkrit yang terjadi di masyarakat (Neuman, 2014).

Konteks sosial dalam penelitian kualitatif merupakan hal kunci yang memberikan makna bagi tindakan sosial, peristiwa ataupun pendapat tergantung saat kemunculannya. Konteks sosial dapat terdiri dari waktu (kapan suatu peristiwa terjadi), lokasi (dimana suatu peristiwa terjadi), emosional (perasaan yang muncul atas suatu peristiwa), sosial-budaya (kondisi sosial maupun budaya saat peristiwa terjadi). Hal-hal ini memberikan warna mendalam bagi peneliti dalam memaknai satu fenomena yang hadir di masyarakat (Neuman, 2014).

\section{ANALISIS DAN DISKUSI}

Sentralisasi penyiaran televisi lebih jauh dijelaskan oleh Ade Armando bagaikan ironi di tengah pertumbuhan ekonomi, siaran televisi hanya berfokus memotret keadaan di Jakarta sehingga hanya tersisa sedikit ruang bagi konten regional maupun lokal yang merefleksikan ketertarikan dan selera penonton di daerah, hal ini terjadi karena stasiun televisi di Indonesia yang berbasis di Jakarta mampu melakukan siaran hingga ke pelosok negeri tanpa perlu mendirikan stasiun lokal (Armando, 2014). Siaran yang Jakartasentris ini menyebabkan penonton di daerah tidak mendapatkan informasi terkait kondisi ekonomi, sosial, politik di wilayahnya sendiri (Armando, 2014).

Dalam tulisannya, Ade Armando menjelaskan bahwa penggunaan frekuensi siaran televisi di Indonesia pada prinsipnya hanya dikuasai oleh sepuluh perusahaan besar di Jakarta dan TVRI sedangkan masyarakat di luar Jakarta hanya menjadi penonton, lebih jauh lagi stasiun televisi swasta nasional di Jakarta mampu menjangkau ratusan juta rakyat Indonesia dengan memanfaatkan frekuensi siaran di daerah-daerah se-Indonesia tanpa menghadirkan manfaat secara ekonomi, politik, sosial, budaya bagi masyarakat di daerah tersebut hal ini mengakibatkan manfaat ekonomi dari industri pertelevisian hanya mengalir ke Jakarta (Armando, 2011).

Isu media yang memusatkan konten di Jakarta turut dibahas dalam riset yang dilakukan oleh Lindawati, menurutnya terdapat dua 
kecenderungan dalam pemberitaan media arus utama pertama dalam bentuk konten yang diangkat oleh media cenderung Jakartasentris dalam hal ini isu-isu daerah kurang menjadi perhatian utama karena pemberitaan media kebanyakan merupakan permasalahan Jakarta dan selalu berkaitan dalam aspek politik, kedua media arus utama sering memarginalkan desa karena pemberitaan tentang desa cenderung bernada negatif misalnya pembahasan terkait kemiskinan, kriminalitas ataupun peristiwa bencana, dalam kata lain desa digambarkan sebagai komunitas yang tidak berdaya (Lindawati, 2014). Pemberitaan tentang desa lebih banyak menempatkan desa sebagai obyek ketimbang subyek yang aktif mengembangkan dirinya sendiri, desa juga diidentikkan dengan masalah bukan sebagai potensi untuk dikembangkan, narasumber terkait isu desa juga lebih banyak mengutamakan pemerintah daerah ketimbang komunitas desa itu sendiri (Lindawati, 2014).

Anggapan bahwa konten media di Indonesia yang Jakartasentris turut diamini oleh salah satu pengamat media yakni almarhum Amir Effendi Siregar, dalam suatu diskusi di tahun 2013 yang digelar di Kementerian Komunikasi dan Informatika, beliau menyampaikan bahwa media banyak menyiarkan konten Jakartasentris karena mengejar rating sehingga tidak ada keberagaman dalam isi berita, terlebih riset terkait rating hanya dilakukan oleh lembaga riset Nielsen yang hanya menjangkau 10 kota besar di Indonesia dan $57 \%$ sampelnya merupakan penonton Jakarta, inilah yang menyebabkan tayangan TV menjadi elitis dan Jakartasentris (Hanum, 2013).

Bukti lain penggambaran tentang Jakarta mendominasi konten media ditunjukkan dalam riset yang dilakukan oleh Centre for Innovation Policy and Governance (CIPG) dtemukan bahwa sebesar $34,1 \%$ konten media melakukan penggambaran tentang Jakarta; sedangkan penggambaran tentang Jawa sebesar 69,9\%. Agama Islam mendominasi konten media dengan penggambaran sebesar 96,7\% dalam keagamaan, selain itu budaya Jawa sebesar $42,8 \%$ mendominasi konten dalam hal etnisitas (Nugroho dkk, 2013).

Penelitian lain yang dilakukan oleh Heychael dan Wibowo pada tahun 2014 terhadap 10 stasiun televisi swasta nasional juga menunjukkan bahwasannya berdasarkan daerah asal berita (tempat terjadinya sebuah peristiwa dilaporkan) $41 \%$ asal berita bersumber dari Jakarta-Bogor-Depok-Tangerang-Bekasi

(Jabodetabek) sementara non-Jabodetabek 48\%, selain itu dari sisi durasi $48 \%$ didominasi Jabodetabek sedangkan non-Jabodetabek 38\%, aspek lain yakni dimensi berita juga didominasi oleh Jabodetabek, berita lokal merujuk pada pemberitaan tentang aktor lokal yakni warga lokal, kepala daerah, tokoh masyarakat setempat, ketua atau anggota organisasi masyarakat setempat, pemerintahan daerah, pengadilan daerah, kepolisian daerah, hasilnya berita lokal Jabodetabek mendominasi pemberitaan 
sebanyak 34\%, dalam temuannya Heychael dan Wibowo mendefinisikan dengan istilah separuh Indonesia adalah Jabodetabek (Heychael \& Wibowo, 2014).

Dalam suatu diskusi yang digelar oleh Centre for Innovation Policy and Governance (CIPG), pengamat media Ignatius Haryanto mengungkapkan bahwa isi televisi di Indonesia terlalu Jakartasentris padahal Indonesia bukan hanya Jakarta, misalnya pemberitaan di televisi terkait banjir Jakarta dengan intensitas tinggi padahal informasi tersebut bisa jadi kurang relevan bagi masyarakat yang tinggal di luar Jakarta, hal ini menunjukkan bagaimana terjadinya bias konten di media penyiaran terlebih lagi televisi yang sangat didominasi oleh informasi dari dan tentang Jakarta, konten selain berita seperti sinetron pun banyak menampilkan halhal seputar Jakarta misalnya dari cara berbicara, masalah yang disuguhkan sangat kental dengan nuansa Jakarta (Yang, 2016).

Televisi dianggap sebagai media yang sempurna untuk melakukan konstruksi terhadap pengetahuan masyarakat karena berfungsi audio-visual, selain itu televisi di masyarakat memiliki posisi legitimasi sosial yang populer karena mampu menghadirkan hal yang dianggap sebagai kebenaran yang mampu mempengaruhi perilaku, sikap hingga pandangan, persepsi, moral, kepribadian dan kebudayaan (Ngadino, 2010). Menurut Mulyo Hadi P selaku Wakil Ketua Komisi Penyiaran Indonesia (KPI), dalam perkembangannya, televisi melakukan penggunaan kata 'lo', 'gue' yang seolah tanpa hal tersebut dianggap kurang kekinian dan kurang metropolis, banyak presenter siaran televisi menggunakan gaya Jakarta saja (Tarigan, 2019).

Salah satu tayangan televisi yang banyak menampilkan tentang Jakarta adalah sinetron ' $\mathrm{Si}$ Doel Anak Sekolahan' yang mengangkat potret keluarga Betawi dimana dalam film tersebut budaya Betawi sangat dipertahankan di tengah modernisasi, sinetron ini juga turut mempromosikan dialek Betawi seperti penggunaan imbuhan akhir 'in' pada kata kerja misalnya dalam bahasa Indonesia 'melestarikan' maka dalam dialek Betawi menjadi 'ngelestariin' ataupun penggunaan kata yang turut dipengaruhi budaya Tionghoa dan Betawi seperti lima ribu dengan kata 'goceng', sepuluh ribu dengan kata 'ceban', dua puluh ribu dengan kata 'noban' ataupun lima puluh ribu dengan kata 'goban', meskipun dialek Betawi tidak jauh berbeda dengan bahasa Indonesia, namun timbul konotasi bahwa dialek Betawi digunakan dalam situasi tidak formal sedangkan bahasa Indonesia untuk situasi formal (Artiyono, 2019).

Pendapat lain terkait Jakartasentris juga diungkapkan oleh Katharina Endriati Sukamto yang merupakan Ketua Masyarakat Linguistik Indonesia, bahwasannya ketika orang daerah memakai ragam Jakarta akan merasa terangkat dan dinilai lebih keren, hal ini disebabkan oleh dominasi ragam Jakarta baik dari sisi jumlah maupun prestise yang ditampilkan oleh tayangan-tayangan televisi misalnya penggunaan 
kata lu, gue, maupun kata-kata berakhiran- 'in' seperti nemen-in, buat-in penggunaan kata tersebut ditiru oleh orang daerah karena dianggap lebih prestise yang dipengaruhi oleh dominasi konten Jakartasentris dalam media yang terkonsentrasi pada hal-hal di ibukota, hal ini menimbulkan semacam ironi karena orang daerah memakai dialek Jakarta karena superioritas. (Artiyono, 2019). Realitas sosial ini terbangun melalui proses eksternalisasi individu dengan individu lainnya yang samasama menonton televisi, yang mengalami objektivasi kemudian signifikansi. Tayangan televisi juga membentuk habituasi di masyarakat dan mendorong tipifikasi karena individu menyetujui yang ditayangkan oleh televisi hingga terjadi pranata sosial yang tetap terjaga melalui legitimasi masyarakat karena sama-sama menonton televisi Jakartasentris hingga hal ini diterima secara luas dan terinternalisasi di individu sebagai suatu kebenaran.

Ditinjau dari pisau analisa teori kultivasi, terpaan yang berulang-ulang dari konten penyiaran Jakartasentris yakni orang daerah yang menganggap dirinya lebih keren jika menggunakan bahasa Jakarta, dampak dari konten yang Jakartasentris ini adalah orang- orang yang berasal dari luar daerah Jakarta akan cenderung dianggap aneh jika muncul di televisi sehingga akan menjadi obyek perundungan atau bully-ing, sebagai contohnya menurut Ignatius Haryanto misalnya kehadiran Arie Kriting yang merupakan salah satu komedian di layar kaca acapkali dianggap aneh, dianggap tidak beres, berbeda (Yang, 2016). Konten Jakartasentris turut memengaruhi konstruksi realitas masyarakat Jakarta sendiri, ketika orang Jakarta berhadapan dengan seseorang yang berasal dari daerah dengan penggunaan logat yang khas atau medok, nyaplak maka cenderung dianggap 'kampungan' hal ini disadari atau tidak mendorong masyarakat luar Jakarta untuk berbahasa ala Jakarta agar dianggap lebih prestisius (Mubarok, 2019). Hal ini terjadi sebagaimana diungkapkan dalam konstruksi sosial realitas dari teori kultivasi arus utama yang meyakini bahwa seringnya seseorang terpapar konten yang disaksikannya di televisi maka akan mempengaruhi konstruksi sosial realitas penonton dimana akan menjadikan penggambaran tentang kehidupan sebagai suatu kebenaran (Gerbner, 1998; Dainton, 2019). 


\section{SIMPULAN}

Konten penyiaran televisi di Indonesia cenderung seragam dan tersentralisasi di Jakarta yang dikenal dengan istilah Jakartasentris. Stasiun-stasiun televisi yang berkantor di Jakarta dapat menyiarkan tayangan dan diakses oleh penduduk Indonesia di berbagai penjuru negeri, ketika menonton televisi maka penduduk Indonesia harus menyaksikan tayangan yang kental dengan nuansa Jakarta dari berbagai unsur, mulai dari pemberitaan tentang Jakarta, gaya hidup Jakarta, tata bahasa Jakarta dan hal lainnya. Keseragaman ini dipicu oleh upaya stasiun televisi dalam mengejar rating yang juga bias Jakarta sehingga memicu keseragaman konten penyiaran di televisi, ironisnya lagi hanya keuntungan tersebut

\section{DAFTAR PUSTAKA}

Armando, Ade. (2011). Televisi Jakarta di Atas Indonesia. Indonesia: Mizan Media Utama.

Armando, Ade. (2014). The Greedy Giants: Centralized Television in Post-Authoritarian Indonesia. International Communication Gazette, 76:390. doi:10.1177/1748048514524106

Artiyono, Sabar. (2019). Lu, Gue dan Fenomena Jakarta Sentris dalam Berbahasa Indonesia. Diakses dari https://kumparan.com/kumparanne ws/lu-gue-dan-fenomena-jakartasentris-dalam-berbahasa-indonesia1qpTVPOEIvR/full pada 13 Desember 2020 pukul 20.02 WIB

Arsan, M. (2016). Sejarah Pertama Kali

Televisi Masuk ke Indonesia.

Diakses dari https://techno.okezone.com/read/20 16/02/16/207/1313559/sejarahpertama-kali-televisi-masuk-ke- hanya dinikmati sebagian besar oleh industri televisi di Jakarta.

Dominasi konten Jakartasentris mengakibatkan masyarakat di luar Jakarta tidak memiliki informasi sosial, ekonomi, politik ataupun kebudayaan di daerahnya sendiri. Sejalan dengan teori kultivasi, terpaan berulang-ulang di televisi yang kontennya Jakartasentris di Indonesia menghasilkan konstruksi sosial realitas masyarakat Indonesia yakni orang di luar Jakarta akan merasa lebih terangkat, keren dan prestise ketika menggunakan gaya Jakarta yang disaksikannya di televisi, sementara orang Jakarta akan menganggap orang yang tidak bergaya Jakarta sebagai 'kampungan' bahkan dianggap aneh.

indonesia pada 9 Desember 2020 pukul 19.07 WIB

Berger, L. Peter \& Luckmann, Thomas. (1966). The Social Construction of Reality: A Treatise in The Sociology of Knowledge. New York: Penguin Books.

Dainton, Marianne \& Zelley, Elaine D. (2019). Applying Communication Theory for Professional Life: a Practical Introduction. 4th Edition. Thousand Oaks: SAGE Publications, Inc

Gerbner, G., Gross, L., Morgan, M., \& Signorielli, N. (1980). The "Mainstreaming" of America: Violence Profile No. 11. Journal of Communication, 30(3), 10-29. doi:10.1111/j.14602466.1980.tb01987.x

Gerbner, G. (1998). Cultivation Analysis: An Overview, Mass Communication and Society, 1:3-4, 
175-194, doi: 10.1080/15205436.1998.9677855

Hanum, Nadia (2013). Rating Nielsen

Bias Jakarta. Diakses dari https://www.remotivi.or.id/kabar/1 06/rating-nielsen-bias-jakarta pada 13 Desember 2020 pukul 18.48 WIB.

Heychael, M. \& Wibowo, A. K. (2014). Melipat Indonesia Dalam Berita Televisi: Kritik Atas Sentralisasi Penyiaran. Indonesia: Publikasi Remotivi.

Ishadi. (2011). Television Industry Dynamics in New Order Era The Effect of Broadcasting Policy Towards News Report. Internasional Journal of Administrative Science \& Organization Vol 18 (2), 133-143.

Koblin, J. (2016). How much do we love TV? Let us count the ways. The New York Times. Diakses dari https://www.nytimes.com/2016/07/ 01/business/media/nielsen-surveymediaviewing.html?mcubz=2\&_r= 0

Laughey, Dan. (2007). Key Themes in Media Theory. New York: McGraw-Hill.

Lindawati, Lisa. (2014). Media Lokal dan Suara Desa: Analisis Isi Surat Kabar Lokal Online di Kabupaten Banyumas. Jurnal Komunikasi Indonesia Vol III (2), 109-118.

Long, Paul \& Wall, Tim. (2012). Media Studies: Texts, Production, Context. 2nd Edition. London: Routledge

Luhmann, N. (2000). The Reality of the Mass Media. Cambridge: Polity.

Merlyna, L. (2012). The League of Thirteen: Media Concentration in Indonesia Research Report. USA: Arizona State University.

Mubarok, Farid. (2019). Sikap Jakarta
Sentris dalam Berbahasa Indonesia. Kajian KSM Eka Prasetya Universitas Indonesia. Diakses dari https://ksm.ui.ac.id/sikap-jakartasentris-dalam-berbahasa-indonesia/ pada 19 Desember 2020 pukul 23.11 WIB

Nabi, R. L. (2009). Cosmetic Surgery Makeover Programs and Intentions to Undergo Cosmetic Enhancements: A Consideration of Three Models of Media Effects. Human Communication Research, 35(1), 1-27. doi:10.1111/j.14682958.2008.01336.x

Neuman, W. Lawrence. (2014). Social Research Methods: Qualitative and Quantitative Approaches 7th Edition. Pearson.

Ngadino, Agus. (2010). Program Televisi Indonesia Dalam Perspektif Hukum Lingkungan. Simbur Cahaya, 43, 2145-2166.

Nugroho, Yanuar dkk. (2013). Produksi Konten, Penentuan Hidup Bersama: Sejauh Mana Media Menjunjung Prinsip

Kewarganegaraan. Indonesia: Centre for Innovation Policy and Governance.

Park, S. J. \& Grow, M. J. (2008). The Social Reality of Depression: DTC Advertising of Antidepressants and Perceptions of the Prevalence and Lifetime Risk of Depression. Journal of Business Ethics, Vol 79, No. 4, 379-393. jstor.org/stable/25482124

Tarigan, M. (2019). KPI Soroti Lo-Gue Gaya Jakarta di TV dan Radio. Diakses dari https://gaya.tempo.co/read/126477 1/kpi-soroti-lo-gue-gaya-jakarta-ditv-dan-radio/full\&view=ok pada 19 Desember 2020 pukul 22.52 WIB

Utami, M. (2015). Cerita Perang Kemerdekaan Indonesia. Indonesia: Wahyu Media.Vergeer, 
Nivedana : Jurnal Komunikasi \& Bahasa

Volume 2, Nomor 1, Juli 2021

M., Lubbers, M., \& Scheepers, P. (2000). Exposure to Newspapers and Attitudes toward Ethnic Minorities: A Longitudinal Analysis. Howard Journal of Communications, 11(2), 127-143. doi:10.1080/106461700246661

Yang, K. C. (2016). Jakartasentris:

Permasalahan Pertelevisian di Indonesia. Diakses dari https://ultimagz.com/event/jakartas entris-permasalahan-pertelevisiandi-indonesia/ pada 13 Desember 2020 pukul 19.18 WIB 